\title{
Breit-Pauli energy levels and transition rates for nitrogen-like and oxygen-like sequences ${ }^{\star, \star \star}$
}

\author{
G. I. Tachiev and C. Froese Fischer
}

\begin{abstract}
Department of Electrical Engineering and Computer Science, Box 1679 B, Vanderbilt University, Nashville, Tennessee 37235, USA

Received 12 October 2001 / Accepted 22 November 2001

Abstract. Breit-Pauli results for energy levels, lifetimes, and Landé $g_{J}$ factors have been determined for all levels up to $2 \mathrm{p}^{2} 3 \mathrm{~d}$ of the nitrogen-like sequence $(Z=7-17)$ and $2 \mathrm{p}^{3} 3 \mathrm{~d}$ of the oxygen-like sequence $(Z=8-20)$. Exceptions are some lower members of the sequence where the spectrum included only those levels below the second $2 \mathrm{p}^{2} 4 \mathrm{~s}$ term in the case of N-like or $2 \mathrm{p}^{3} 4 \mathrm{~s}$ in the case of O-like. The computed energy and E1, E2, M1, M2 transition data between all levels, including convergence of the LS line strength for both length and velocity forms, may be viewed at a website. In this paper, critically evaluated transition data is presented for N I, O II, Mg VI, and Si VIII (N-like sequence) and O I, Ne III, Mg V, and Si VII (O-like) for E1 transitions including uncertainty estimates. The accuracy of energy levels is determined by comparison with experiment. Transition rates with uncertainties are compared with experiment and other theory.
\end{abstract}

Key words. atomic data - atomic processes

\section{Introduction}

Transition data is important in many astrophysical applications. With the formation of the Opacity Project, under the leadership of Seaton (1987), large amounts of E1 transition data have been generated through an international collaboration, mostly for light atoms. Some of this data has been checked by Bell \& Hibbert (1990), Hibbert et al. (1991a, 1991b), and Bell et al. (1994) with the CIV3 code by including some of the Breit-Pauli operators. The critical data compilation for carbon, nitrogen, and oxygen, prepared at NIST by Wiese et al. (1996), includes many of these values with accuracy ratings obtained through comparison with experiment and other theory, when available. Transitions deemed to be accurate to $10 \%$ were given an uncertainty rating of "B". Many did not reach this accuracy level.

Using the power of today's computers, including parallel computers, we have started to systematically compute all the energy levels of the lower portion of a spectrum, defined as being all levels below $2 \mathrm{~s}^{2} 2 \mathrm{p}^{m} 4 \mathrm{~s}, m=0,1, \ldots, 5$ for a range of nuclear charges. From the wave functions

\footnotetext{
Send offprint requests to: C. Froese Fischer, e-mail: Charlotte.F.Fischer@Vanderbilt.edu

* Research supported by the Chemical Sciences, Geosciences, and Biosciences Division, Office of Basic Energy Sciences, Office of Science, U.S. Department of Energy.

$\star \star$ Tables 4 and 5 are only available in electronic form at the CDS via anonymous ftp to cdsarc.u-strasbg.fr (130.79.128.5) or via

http://cdsweb.u-strasbg.fr/cgi-bin/qcat?J/A+A/385/716
}

of these levels, all possible transitions (E1, E2, M1, M2) were computed and from these, in turn, the lifetimes of the levels which, for excited states, relate more directly with experiment.

Our goal also was to perform calculations in such a way that accuracy could be monitored. Energies can be compared with observation (except for highly ionized systems where data often is missing) but energy alone is not sufficient. We also monitored the length and velocity forms of the LS line strength. Attempts were made to reach convergence with respect to the wave function expansion model: if convergence had been reached but length and velocity are not in agreement, this indicated an inaccuracy in our computational model. From the final results we developed formulas for an uncertainty. Critically evaluated results have been reported by the present authors (Tachiev \& Fischer 1999 (Be-like), 2000 (B-like), and 2001 (C-like)). In this paper we report our analysis of both N-like $(Z=7-17)$ and O-like $(Z=8-20)$, restricting the transition rates to E1 transitions only. The complete set of results, including the Landé $g_{\mathrm{J}}$ factors, are available at the website http://www .vuse.vanderbilt.edu/ ${ }^{\sim} \mathrm{cff} /$ mchf_collection

\section{Theory}

The underlying procedures are the same as those described in detail in our Be-like paper (Tachiev \& Froese Fischer 1999) and will not be repeated here.

Systematic, large-scale methods were applied in which the wave function expansions were obtained from orbital 
sets of increasing size characterized by their maximum quantum number, thereby allowing for the monitoring of convergence. For orbital sets with $n=4$ or $n=5$, these were obtained, by single (S) and double (D) excitations from a multi-reference set. In all cases, $1 \mathrm{~s}^{2}$ was treated as a common closed core. The multi-reference set contained all configurations $\left\{2 \mathrm{~s}^{2} 2 \mathrm{p}^{m}\right.$ or $\left.2 \mathrm{p}^{m+2}\right\}\{2 \mathrm{p}, 3 \mathrm{~s}, 3 \mathrm{p}, 3 \mathrm{~d}, 4 \mathrm{~s}, 4 \mathrm{p}, 4 \mathrm{~d}\}$ and $2 \mathrm{~s} 2 \mathrm{p}^{m+1}\{2 \mathrm{p}, 3 \mathrm{~s}, 3 \mathrm{p}, 3 \mathrm{~d}\}$ with the designated term and parity where $m=2$ for N-like and $m=3$ for Olike. Only those configuration states from SD excitations which interacted with at least one member of the multi-reference set were retained. To these expansions were added all configuration states of the form $1 \mathrm{~s}^{2} \cdot\{2\}^{m+1}\{2 \mathrm{~s}, 2 \mathrm{p}, \ldots, 6 \mathrm{~s}, 6 \mathrm{p}, 6 \mathrm{~d}, 6 \mathrm{f}, 6 \mathrm{~g}\}^{2}$ at the $n=6$ stage and then $1 \mathrm{~s}^{2} \cdot\{2\}^{m+1}\{2 \mathrm{~s}, 2 \mathrm{p}, \ldots, 7 \mathrm{~s}, 7 \mathrm{p}, 7 \mathrm{~d}, 7 \mathrm{f}, 7 \mathrm{~g}\}^{2}$ at the $n=$ 7 stage. In this notation $\{2\}^{m+1}$ implies any combination of $2 \mathrm{~s}, 2 \mathrm{p}$ orbitals which, when coupled to two of the orbitals in the last orbital set, yields the required term and parity.

Once a set of radial orbitals has been obtained, the relativistic corrections can be taken into account within the Breit-Pauli approximation by diagonalizing the BreitPauli Hamiltonian (Froese Fischer 1997) to get the intermediate coupling wave functions

$\Psi(\gamma J)=\sum_{L S} \sum_{j} c_{j}(L S J) \Phi\left(\gamma_{j} L S J\right)$.

Thus the expansion is now the sum of expansions over a set of terms. The wave functions were obtained from a Breit-Pauli interaction matrix that omitted only the $J$-independent, orbit-orbit interaction which then behaves much like neglected $L S$ correlation.

The oscillator strengths $f$ are calculated using the standard, non-relativistic operators for length and velocity forms (see Tachiev \& Froese Fischer 1999, for details). The non-relativistic line strengths allow us to monitor the convergence between the two forms with the improvement of the wave functions. In the Breit-Pauli approximation, the same length form is correct to $O\left(\alpha^{2}\right)$ while the velocity form requires a relativistic correction to the gradient operator (Drake 1972). For this reason, it is customary to report both length and velocity results for an $L S$ calculation, but only the length form in the Breit-Pauli calculation. No orthonormality constraints are imposed between the two sets of radial functions spanning the total wave functions of the initial and final state, allowing separate MCHF optimizations for the two states involved.

\section{Optimization}

The different states of the ions were grouped together and a radial basis determined for a set of terms and/or eigenvalues that were deemed to be important for the relativistic effects. In Table 1, for each system are the group of terms for which accurate Breit-Pauli results are required. But because these may mix with additional terms, the latter are listed in the second group. Sometimes these are different eigenfunctions of the same term and this is indicated by the configuration. Mixing with some of the terms
Table 1. Optimization strategies for groups of terms. Eigenfunctions for a specific term are designated by the dominant configuration. All weights are unity unless designated otherwise in parenthesis following the term.

\begin{tabular}{ll}
\hline \hline \multicolumn{1}{c}{ Config. } & \multicolumn{1}{c}{ Terms } \\
\hline Even & \multicolumn{1}{c}{$N$-like } \\
First Group: & ${ }^{2} \mathrm{~S},{ }^{2} \mathrm{P},{ }^{2} \mathrm{~S},{ }^{4} \mathrm{P}$ \\
2s2p $\mathrm{p}^{4}$ & \\
Second Group: & \\
$2 \mathrm{p}^{2}\left({ }^{3} \mathrm{P}\right) 3 \mathrm{~s}$ & ${ }^{2} \mathrm{P},{ }^{2} \mathrm{D},{ }^{4} \mathrm{P}$ \\
$2 \mathrm{p}^{2}\left({ }^{1} \mathrm{~S}\right) 3 \mathrm{~s}$ & ${ }^{2} \mathrm{~S}$ \\
Third Group: & \\
$2 \mathrm{p}^{2}\left({ }^{3} \mathrm{P}\right) 3 \mathrm{~d}$ & ${ }^{2} \mathrm{P},{ }^{2} \mathrm{D},{ }^{2} \mathrm{~F},{ }^{4} \mathrm{P},{ }^{4} \mathrm{D},{ }^{4} \mathrm{~F}$ \\
$2 \mathrm{p}^{2}\left({ }^{1} \mathrm{D}\right) 3 \mathrm{~d}$ & ${ }^{2} \mathrm{~S},{ }^{2} \mathrm{P},{ }^{2} \mathrm{D},{ }^{2} \mathrm{~F},{ }^{2} \mathrm{G}$ \\
$2 \mathrm{~s} 2 \mathrm{p}^{3}\left({ }^{5} \mathrm{~S}\right) 3 \mathrm{p}$ & ${ }^{4} \mathrm{P}$ \\
$2 \mathrm{p}^{2}\left({ }^{1} \mathrm{~S}\right) 3 \mathrm{~d}$ & ${ }^{2} \mathrm{D}$ \\
Odd & \\
First Group: & \\
$2 \mathrm{p}^{3}$ & ${ }^{2} \mathrm{P}^{\mathrm{o}},{ }^{2} \mathrm{D}^{\mathrm{o}},{ }^{4} \mathrm{P}^{\mathrm{o}}$ \\
Second Group: & \\
$2 \mathrm{p}^{5}$ & ${ }^{2} \mathrm{P}^{\mathrm{o}}$ \\
Third Group: & \\
$2 \mathrm{p}^{2}\left({ }^{3} \mathrm{P}\right) 3 \mathrm{p}$ & ${ }^{2} \mathrm{~S}^{\mathrm{o}},{ }^{2} \mathrm{P}^{\mathrm{o}},{ }^{2} \mathrm{D}^{\mathrm{o}},{ }^{4} \mathrm{~S}^{\mathrm{o}},{ }^{4} \mathrm{P}^{\mathrm{o}}, \quad{ }^{4} \mathrm{D}^{\mathrm{o}}$ \\
$2 \mathrm{p}^{2}\left({ }^{1} \mathrm{D}\right) 3 \mathrm{p}$ & ${ }^{2} \mathrm{P}^{\mathrm{o}},{ }^{2} \mathrm{D}^{\mathrm{o}},{ }^{2} \mathrm{~F}^{\mathrm{o}}$ \\
$2 \mathrm{p}^{3}\left({ }^{5} \mathrm{~S}\right) 3 \mathrm{~s}$ & ${ }^{4} \mathrm{~S}^{\mathrm{o}}$ \\
$2 \mathrm{p}^{2}\left({ }^{1} \mathrm{~S}\right) 3 \mathrm{p}$ & ${ }^{2} \mathrm{P}^{\mathrm{o}}$ \\
\hline & \multicolumn{1}{c}{$\mathrm{O}-$ like } \\
\hline
\end{tabular}

$\begin{array}{ll}\text { Even } & \\ \text { First Group: } & \\ 2 \mathrm{p}^{4} & { }^{1} \mathrm{~S},{ }^{1} \mathrm{D},{ }^{3} \mathrm{P} \\ \text { Second Group: } & \\ 2 \mathrm{p}^{6} & { }^{1} \mathrm{~S} \\ \text { Third Group: } & \\ 2 \mathrm{p}\left({ }^{4} \mathrm{~S}\right) 3 \mathrm{p} & { }^{5} \mathrm{P} \\ 2 \mathrm{p}^{3}\left({ }^{2} \mathrm{D}\right) 3 \mathrm{p} & { }^{1} \mathrm{P},{ }^{1} \mathrm{D},{ }^{1} \mathrm{~F},{ }^{3} \mathrm{P},{ }^{3} \mathrm{D},{ }^{3} \mathrm{~F} \\ 2 \mathrm{p}^{3}\left({ }^{2} \mathrm{P}\right) 3 \mathrm{p} & { }^{1} \mathrm{~S},{ }^{1} \mathrm{P},{ }^{1} \mathrm{D},{ }^{3} \mathrm{~S},{ }^{3} \mathrm{P},{ }^{3} \mathrm{D} \\ 2 \mathrm{~s} 2 \mathrm{p}^{4}\left({ }^{4} \mathrm{P}\right) 3 \mathrm{~s} & { }^{5} \mathrm{P} \\ \text { Oddd } & \\ \text { First Group: } & \\ 2 \mathrm{~s} 2 \mathrm{p}^{5} & { }^{3} \mathrm{P}^{\mathrm{o}},{ }^{1} \mathrm{P}^{\mathrm{o}} \\ \text { Second Group: } & \\ 2 \mathrm{p}^{3}\left({ }^{4} \mathrm{~S}\right) 3 \mathrm{~s} & { }^{5} \mathrm{~S}^{\mathrm{o}},{ }^{3} \mathrm{~S}^{\mathrm{o}} \\ 2 \mathrm{p}^{3}\left({ }^{2} \mathrm{D}\right) 3 \mathrm{~s} & { }^{1} \mathrm{P}^{\mathrm{o}},{ }^{1} \mathrm{D}^{\mathrm{o}},{ }^{3} \mathrm{P}^{\mathrm{o}},{ }^{3} \mathrm{D}^{\mathrm{o}} \\ \text { Third Group: } & \\ 2 \mathrm{p}^{3}\left({ }^{4} \mathrm{~S}\right) 3 \mathrm{~d} & { }^{3} \mathrm{D}^{\mathrm{o}},{ }^{5} \mathrm{D}^{\mathrm{o}}, \\ 2 \mathrm{p}^{3}\left({ }^{2} \mathrm{D}\right) 3 \mathrm{~d} & { }^{1} \mathrm{~S}^{\mathrm{o}},{ }^{1} \mathrm{P}^{\mathrm{o}},{ }^{1} \mathrm{D}^{\mathrm{o}},{ }^{1} \mathrm{~F}^{\mathrm{o}},{ }^{1} \mathrm{G}^{\mathrm{o}},{ }^{3} \mathrm{~S}^{\mathrm{o}} \\ 2 \mathrm{p}^{3}\left({ }^{2} \mathrm{P}\right) 3 \mathrm{~d} & { }^{3} \mathrm{P}^{\mathrm{o}},{ }^{3} \mathrm{D}^{\mathrm{o}},{ }^{3} \mathrm{~F}^{\mathrm{o}},{ }^{3} \mathrm{G}^{\mathrm{o}},{ }^{1} \mathrm{D}^{\mathrm{o}},{ }^{1} \mathrm{~F}^{\mathrm{o}},{ }^{3} \mathrm{P}^{\mathrm{o}},{ }^{3} \mathrm{D}^{\mathrm{o}},{ }^{3} \mathrm{~F}^{\mathrm{o}} \\ 2 \mathrm{p}^{3}\left({ }^{4} \mathrm{~S}\right) 4 \mathrm{~s} & { }^{3} \mathrm{~S}^{\mathrm{o}},{ }^{5} \mathrm{~S}^{\mathrm{o}} \\ \end{array}$

may not be particularly strong. In such cases these LS eigenstates had a smaller weight as indicated in Table 1. The neutral atom and singly ionized ion have a somewhat different spectrum. States with 4 s lie much lower in the spectrum and $2 \mathrm{p}^{m+3}$ much higher. Since the lowest $2 \mathrm{p}^{m} 4 \mathrm{~s}$ may interact strongly with the corresponding $2 \mathrm{p}^{m} 3 \mathrm{~d}$, this term has also been considered in such cases. Here, as in 
Table 2. Some computed energies and energy difference (computed - observed) (in $\mathrm{s}^{-1}$ ) for excited states up to $2 \mathrm{~s}^{2} 2 \mathrm{p}^{2}\left({ }^{3} \mathrm{P}\right) 3 \mathrm{~d}$ ${ }^{2} \mathrm{D}$ of N-like systems for N I, O II, Mg VI.

\begin{tabular}{|c|c|c|c|c|c|c|c|}
\hline \multirow[t]{2}{*}{ Config. } & & \multicolumn{2}{|c|}{ N I } & \multicolumn{2}{|c|}{ O II } & \multicolumn{2}{|c|}{ Mg VI } \\
\hline & & Computed & diff & Computed & diff & Computed & diff \\
\hline \multirow[t]{5}{*}{$2 \mathrm{p}^{3}$} & ${ }^{4} \mathrm{~S}_{3 / 2}^{\mathrm{o}}$ & & & & & & \\
\hline & ${ }^{2} \mathrm{D}_{3 / 2}^{\mathrm{o}}$ & 19381.08 & 147.90 & 27042.42 & 211.85 & 55758.69 & 385.89 \\
\hline & ${ }^{2} \mathrm{D}_{5 / 2}^{\mathrm{o}}$ & 19372.37 & 147.91 & 27022.72 & 212.17 & 55750.15 & 394.15 \\
\hline & ${ }^{2} \mathrm{P}_{1 / 2}^{\mathrm{o}}$ & 28905.04 & 66.12 & 40576.95 & 106.95 & 84106.12 & 186.12 \\
\hline & ${ }^{2} \mathrm{P}_{3 / 2}^{\mathrm{o}}$ & 28905.07 & 65.76 & 40574.37 & 106.36 & 84212.17 & 183.77 \\
\hline \multirow[t]{3}{*}{$2 \mathrm{~s} 2 \mathrm{p}^{4}$} & ${ }^{4} \mathrm{P}_{5 / 2}$ & 88095.07 & -12.19 & 120076.70 & 239.49 & 248609.80 & 661.80 \\
\hline & ${ }^{4} \mathrm{P}_{3 / 2}$ & 88140.45 & -10.72 & 120237.00 & 236.57 & 250237.90 & 653.90 \\
\hline & ${ }^{4} \mathrm{P}_{1 / 2}$ & 88160.84 & -9.73 & 120317.50 & 234.64 & 251094.20 & 644.20 \\
\hline \multirow[t]{5}{*}{$2 \mathrm{p}^{2}\left({ }^{3} \mathrm{P}\right) 3 \mathrm{~s}$} & ${ }^{4} \mathrm{P}_{1 / 2}$ & 82877.41 & -406.66 & 184877.80 & -357.48 & 893491.30 & -448.70 \\
\hline & ${ }^{4} \mathrm{P}_{3 / 2}$ & 82911.92 & -405.91 & 184981.30 & -359.28 & 894509.50 & -380.50 \\
\hline & ${ }^{4} \mathrm{P}_{5 / 2}$ & 82960.81 & -403.81 & 185136.30 & -362.82 & 896020.70 & -419.30 \\
\hline & ${ }^{2} \mathrm{P}_{1 / 2}$ & 85672.83 & -464.52 & 188604.70 & -283.84 & 908117.40 & -292.60 \\
\hline & ${ }^{2} \mathrm{P}_{3 / 2}$ & 85753.52 & -466.99 & 188782.00 & -286.51 & 909969.10 & -330.90 \\
\hline \multirow[t]{2}{*}{$2 \mathrm{p}^{2}\left({ }^{1} \mathrm{D}\right) 3 \mathrm{~s}$} & ${ }^{2} \mathrm{D}_{5 / 2}$ & 99357.82 & -305.61 & 206877.70 & -93.98 & 938823.10 & -6.90 \\
\hline & ${ }^{2} \mathrm{D}_{3 / 2}$ & 99358.41 & -305.50 & 206878.70 & -94.02 & 938851.30 & 21.30 \\
\hline $2 \mathrm{p}^{2}\left({ }^{1} \mathrm{~S}\right) 3 \mathrm{~s}$ & ${ }^{2} \mathrm{~S}_{1 / 2}$ & - & - & 230623.30 & 13.85 & 983404.90 & -15.10 \\
\hline \multirow[t]{6}{*}{$2 \mathrm{p}^{2}\left({ }^{3} \mathrm{P}\right) 3 \mathrm{~d}$} & ${ }^{2} \mathrm{P}_{3 / 2}$ & 104184.50 & -430.97 & 233331.10 & -99.43 & 1039820.00 & -240.00 \\
\hline & ${ }^{2} \mathrm{P}_{1 / 2}$ & 104215.10 & -438.93 & 233447.90 & -96.69 & 1042100.00 & 1420.00 \\
\hline & ${ }^{4} \mathrm{D}_{1 / 2}$ & 104545.80 & -438.57 & 232379.30 & -332.34 & 1040474.00 & -5146.00 \\
\hline & ${ }^{4} \mathrm{D}_{5 / 2}$ & 104569.60 & -438.95 & 232415.60 & -331.96 & 1041264.00 & -3946.00 \\
\hline & ${ }^{4} \mathrm{D}_{3 / 2}$ & 104557.90 & -438.37 & 232412.60 & -333.38 & 1041354.00 & -3856.00 \\
\hline & ${ }^{4} \mathrm{D}_{7 / 2}$ & 104577.50 & -440.10 & 232420.70 & -333.12 & 1041752.00 & - \\
\hline \multirow[t]{7}{*}{$2 \mathrm{p}^{2}\left({ }^{3} \mathrm{P}\right) 3 \mathrm{~d}$} & ${ }^{2} \mathrm{~F}_{5 / 2}$ & 104362.40 & -447.96 & 232465.00 & -331.30 & 1046330.00 & -90.00 \\
\hline & ${ }^{2} \mathrm{~F}_{7 / 2}$ & 104430.10 & -451.25 & 232625.90 & -333.31 & 1048280.00 & -100.00 \\
\hline & ${ }^{4} \mathrm{P}_{5 / 2}$ & 104400.60 & -424.51 & 232133.00 & -329.72 & 1047111.00 & -199.00 \\
\hline & ${ }^{4} \mathrm{P}_{3 / 2}$ & 104435.40 & -424.33 & 232206.10 & -329.85 & 1047816.00 & -174.00 \\
\hline & ${ }^{4} \mathrm{P}_{1 / 2}$ & 104461.60 & -424.50 & 232271.60 & -330.89 & 1048183.00 & -197.00 \\
\hline & ${ }^{2} \mathrm{D}_{3 / 2}$ & 104661.90 & -457.98 & 234087.10 & -315.70 & 1062037.00 & -13.00 \\
\hline & ${ }^{2} \mathrm{D}_{5 / 2}$ & 104685.10 & -458.61 & 234135.60 & -319.03 & 1062590.00 & -30.00 \\
\hline
\end{tabular}

the rest of the paper, the $2 \mathrm{~s}^{2}$ group of electrons will be omitted in the designation of the configuration.

\section{Computed energies}

One check on the accuracy of the calculations are the computed energies. Tables 2 and 3 display the ab initio excitation energies (in $\mathrm{cm}^{-1}$ ) along with the difference from experiment (theory-observed) of some of the levels. Only selected spectra are included namely, N I, O II, and Mg VI for N-like and $\mathrm{O}$ I, Ne III, and $\mathrm{Mg} \mathrm{V}$ for O-like. When blanks occur in the computed spectra, the levels were not in the spectral region included in this work, but when a difference is not tabulated, this implies that observed energies were not available. Particularly in $\mathrm{Mg} \mathrm{V}$ and VI, many observed lines have not been tabulated. In order to limit the combined size of these tables to one page, not all the spectrum is shown. The tables show that many levels differ from observed by only $300-400 \mathrm{~cm}^{-1}$, but exceptions occur. In $2 \mathrm{~s} 2 \mathrm{p}^{4}$ the higher terms are always less accurate. To some extent, this may be due to our computational model which was tailored more towards the levels with one outer 31 electron. The relative error in the excitation energies is not a particularly useful measure since, by definition, highly excited states can then have large differences from observed leading to possible larger errors in transition energies.

In Fig. 1 we have plotted the errors (in percent) for some transitions where energy levels have been included in the NIST database for transitions in the O-like sequence. Clearly evident is the large error for neutral and singly ionized transition energies. For $3 \mathrm{~s}-3 \mathrm{p}$ and $3 \mathrm{p}-3 \mathrm{~d}$ transitions, available data is limited. The errors for $2 \mathrm{p}-3 \mathrm{~s}$ and $2 \mathrm{p}-3 \mathrm{~d}$ transition energies are small because the transition energies are large, particularly at higher $Z$. The error in the $2 \mathrm{~s}-2 \mathrm{p}$ transition, indicated by the "star", increases almost linearly with $Z$. This is an "inner" transition (an inner electron is excited to an outer one), a transition more sensitive to core-polarization at low $Z$, and more likely to be affected by higher-order relativistic effects at high $Z$. But on the whole, the accuracy of the transition energies for all but the neutral atom is well below $1 \%$ in this range for these $L S$ allowed transitions. When transition energies are small, the errors can be expected to be larger as, for example, $2 \mathrm{~s} 2 \mathrm{p}^{5}{ }^{1} \mathrm{P}_{1}^{\mathrm{o}}-2 \mathrm{p}^{3}\left({ }^{2} \mathrm{D}\right) 3 \mathrm{p}^{3} \mathrm{P}_{2}$ where the transition energy is only $1363 \mathrm{~cm}^{-1}$ and the error is $-86.55 \%$ in F II 
Table 3. Some computed energies and energy difference (computed - observed in $s^{-1}$ ) for excited states up to $2 s^{2} 2 p^{3}\left({ }^{4} S\right) 3 d$ ${ }^{3} \mathrm{D}$ of O-like systems for O I, Ne III, Mg V

\begin{tabular}{|c|c|c|c|c|c|c|c|}
\hline \multirow[t]{2}{*}{ Config. } & & \multicolumn{2}{|c|}{ O I } & \multicolumn{2}{|c|}{ Ne III } & \multicolumn{2}{|c|}{$\mathrm{Mg} \mathrm{V}$} \\
\hline & & Computed & diff & Computed & diff & Computed & diff \\
\hline \multirow[t]{5}{*}{$2 \mathrm{p}^{4}$} & ${ }^{3} \mathrm{P}_{2}$ & & & & - & & \\
\hline & ${ }^{3} \mathrm{P}_{1}$ & 156.04 & -2.22 & 638.31 & -4.59 & 1778.25 & -4.85 \\
\hline & ${ }^{3} \mathrm{P}_{0}$ & 223.32 & -3.66 & 911.62 & -8.88 & 2506.75 & -15.05 \\
\hline & ${ }^{1} \mathrm{D}_{2}$ & 16122.31 & 254.45 & 26097.05 & 256.25 & 36207.22 & 281.22 \\
\hline & ${ }^{1} \mathrm{~S}_{0}$ & 33844.21 & 51.63 & 55771.96 & 21.36 & 77291.19 & 12.19 \\
\hline \multirow[t]{4}{*}{$2 \mathrm{~s} 2 \mathrm{p}^{5}$} & ${ }^{3} \mathrm{P}_{2}^{\mathrm{o}}$ & - & - & 204717.90 & 425.90 & 283885.00 & 672.70 \\
\hline & ${ }^{3} \mathrm{P}_{1}^{\mathrm{o}}$ & - & - & 205296.70 & 417.70 & 285496.00 & 667.70 \\
\hline & ${ }^{3} \mathrm{P}_{0}^{\mathrm{o}}$ & - & - & 205616.60 & 412.60 & 286374.90 & 662.90 \\
\hline & ${ }^{1} \mathrm{P}_{1}^{\mathrm{o}}$ & - & - & 290702.50 & 1223.50 & 399069.20 & 1587.20 \\
\hline \multirow[t]{2}{*}{$2 \mathrm{p}^{3}\left({ }^{4} \mathrm{~S}\right) 3 \mathrm{~s}$} & ${ }^{5} \mathrm{~S}_{2}^{\mathrm{o}}$ & 74011.77 & 243.57 & 309774.50 & -149.50 & 668750.80 & - \\
\hline & ${ }^{3} \mathrm{~S}_{1}^{\mathrm{o}}$ & 76909.81 & 114.83 & 319244.50 & -200.40 & 684358.70 & -182.30 \\
\hline \multirow[t]{4}{*}{$2 \mathrm{p}^{3}\left({ }^{2} \mathrm{D}\right) 3 \mathrm{~s}$} & ${ }^{3} \mathrm{D}_{3}^{\mathrm{O}}$ & - & - & 353306.60 & 158.60 & 727961.20 & 219.20 \\
\hline & ${ }^{3} \mathrm{D}_{2}^{\mathrm{o}}$ & - & - & 353335.80 & 158.64 & 727977.50 & 214.50 \\
\hline & ${ }^{3} \mathrm{D}_{1}^{\mathrm{o}}$ & - & - & 353355.70 & 158.30 & 727999.50 & 217.50 \\
\hline & ${ }^{1} \mathrm{D}_{2}^{\mathrm{o}}$ & - & - & 358158.40 & 228.40 & 735852.30 & 306.30 \\
\hline \multirow[t]{4}{*}{$2 \mathrm{p}^{3}\left({ }^{2} \mathrm{P}\right) 3 \mathrm{~s}$} & ${ }^{3} \mathrm{P}_{2}^{\mathrm{o}}$ & - & - & 374629.80 & 195.80 & 756777.10 & 136.10 \\
\hline & ${ }^{3} \mathrm{P}_{1}^{\mathrm{o}}$ & - & - & 374624.40 & 163.65 & 756691.00 & 125.00 \\
\hline & ${ }^{3} \mathrm{P}_{0}^{\mathrm{o}}$ & - & - & 374625.70 & 148.04 & 756663.30 & 118.30 \\
\hline & ${ }^{1} \mathrm{P}_{1}^{\mathrm{o}}$ & - & - & 380068.80 & 234.80 & 764879.00 & 251.00 \\
\hline \multirow[t]{8}{*}{$2 \mathrm{p}^{3}\left({ }^{4} \mathrm{~S}\right) 3 \mathrm{~d}$} & ${ }^{5} \mathrm{D}_{4}^{\mathrm{O}}$ & 97271.99 & -273.31 & 394761.60 & 38.62 & 811372.60 & - \\
\hline & ${ }^{5} \mathrm{D}_{3}^{\mathrm{o}}$ & 97271.52 & -273.88 & 394764.40 & 39.89 & 811377.80 & - \\
\hline & ${ }^{5} \mathrm{D}_{2}^{\mathrm{o}}$ & 97271.66 & -273.87 & 394767.50 & 39.16 & 811386.00 & - \\
\hline & ${ }^{5} \mathrm{D}_{1}^{\mathrm{o}}$ & 97271.99 & -273.64 & 394770.00 & 38.25 & 811393.10 & - \\
\hline & ${ }^{5} \mathrm{D}_{0}^{\mathrm{o}}$ & 97272.22 & -273.46 & 394771.40 & - & 811397.10 & - \\
\hline & ${ }^{3} \mathrm{D}_{1}^{\mathrm{o}}$ & 97208.30 & -283.46 & 398185.30 & -7.40 & 821989.50 & 15.50 \\
\hline & ${ }^{3} \mathrm{D}_{2}^{\mathrm{o}}$ & 97208.64 & -283.19 & 398190.00 & -6.83 & 822006.40 & 17.40 \\
\hline & ${ }^{3} \mathrm{D}_{3}^{\mathrm{o}}$ & 97208.57 & -283.35 & 398202.80 & -7.94 & 822090.00 & 24.00 \\
\hline
\end{tabular}

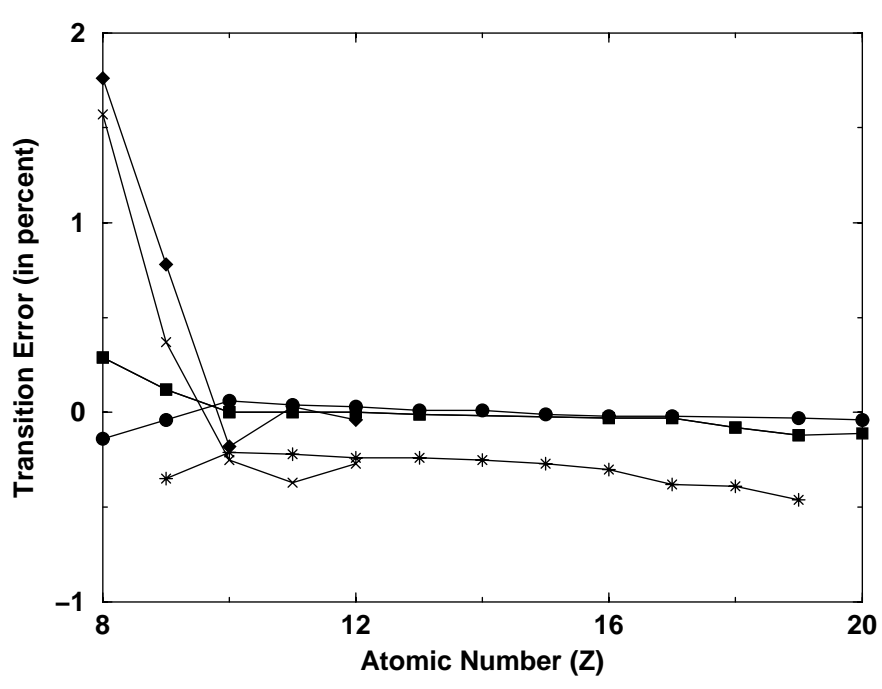

Fig. 1. Percent error in the ab initio transition energy. Symbols: Star $-2 \mathrm{p}^{4}{ }^{3} \mathrm{P}_{2}-2 \mathrm{~s} 2 \mathrm{p}^{5}{ }^{3} \mathrm{P}_{2}^{\mathrm{o}}$; circle $-2 \mathrm{p}^{4}{ }^{3} \mathrm{P}_{2}-2 \mathrm{p}^{3}\left({ }^{4} \mathrm{~S}\right) 3 \mathrm{~s}$ ${ }^{3} \mathrm{~S}_{1}^{\mathrm{o}}$; square $-2 \mathrm{p}^{4}{ }^{3} \mathrm{P}_{2}-2 \mathrm{p}^{3}\left({ }^{4} \mathrm{~S}\right) 3 \mathrm{~d}{ }^{3} \mathrm{P}_{2}^{\mathrm{o}}$; diamond $-2 \mathrm{p}^{3}\left({ }^{4} \mathrm{~S}\right) 3 \mathrm{~s}$ ${ }^{5} \mathrm{~S}_{2}^{\mathrm{o}}-2 \mathrm{p}^{3}\left({ }^{4} \mathrm{~S}\right) 3 \mathrm{p}{ }^{5} \mathrm{P}_{3} ; \operatorname{cross}-2 \mathrm{p}^{3}\left({ }^{4} \mathrm{~S}\right) 3 \mathrm{p}{ }^{5} \mathrm{P}_{1}-2 \mathrm{p}^{3}\left({ }^{4} \mathrm{~S}\right) 3 \mathrm{~d}{ }^{5} \mathrm{D}_{2}^{\mathrm{o}}$.

but has already decreased to $0.35 \%$ in Ne III. Generally, the errors decrease with the degree of ionization, although at some point, the Breit-Pauli approximation must break down. Some evidence of this is seen in Fig. 1.

\section{LS accuracies}

Unlike the C-like sequence, the present sequences are ones where, for a given term and outer electron, there may be more than one parent as in $2 \mathrm{p}^{2} 3 \mathrm{p}^{2} \mathrm{D}^{\mathrm{o}}$ which may have a $2 \mathrm{p}^{2}\left({ }^{3} \mathrm{P}\right)$, or $2 \mathrm{p}^{2}\left({ }^{1} \mathrm{D}\right)$ parent. When the mixing of parents is strong, the separation of the two should be close to observed. In O II, for example, the error in the separation of $2 \mathrm{p}^{2}\left({ }^{3} \mathrm{P}\right) 3 \mathrm{p} \quad{ }^{2} \mathrm{P}^{\mathrm{o}}$ and $2 \mathrm{p}^{2}\left({ }^{1} \mathrm{D}\right) 3 \mathrm{p} \quad{ }^{2} \mathrm{P}^{\mathrm{o}}$ is about $1.8 \%$ implying that the mixing of the parents has similar accuracy. This may then affect the accuracy of parent changing transitions. For this reason, in critical cases, it is the separation of levels that is important rather than excitation energies as such.

\section{Computed transitions and uncertainties}

In each of our papers (Tachiev \& Froese Fischer 1999, 2000, 2001) we have devised schemes for estimating accuracy of transition rates, based on the discrepancy in length and velocity of the $L S$ allowed transition, the accuracy of the transition energy, and the change in transition rate when term energies were adjusted to observed energies. For complex systems with many transitions, some being intercombination lines, two formulas were used for the uncertainty in line strength 
(see Tachiev \& Froese Fischer 2001, for details). Let $A$ be the ab initio value of a transition rate, $A^{\prime}$ the rate using the same line strength, but observed transition energy, and $A^{\prime \prime}$ the rate obtained when the Breit-Pauli diagonalization contains shifts for the different terms related to the difference between observed and ab initio for a $J$-value least affected by term mixing. From Tables 2 and 3, often the shifts were small and of the same size. The latter would not significantly affect term mixing. Then the uncertainty in $A^{\prime \prime}$ was defined as

$$
\left|A^{\prime}-A^{\prime \prime}\right|+(\delta e+\delta S) A^{\prime \prime}
$$

where $\delta e$ is the relative error in the transition energy, and $\delta S$ a relative error in the line strength. For $L S$ allowed transitions, this is the relative discrepancy in the length and velocity form, but for an intercombination line a more complex definition was needed. One could argue that the quantity $\left|A^{\prime}-A^{\prime \prime}\right|$ should not be included since $A^{\prime \prime}$ is an improved estimate, that the above is an estimate of the uncertainty in $A^{\prime}$. In fact, it is not clear how well this uncertainty correlates with the actual error, but appears reasonable in many cases.

\section{Computed transition rates}

In Table 4 we present adjusted transition rates $\left(\right.$ in $\mathrm{s}^{-1}$ ) and uncertainties (in parentheses) for N I, O II, Mg VI, and Si IX. Not all transitions are included: for example transitions from $2 \mathrm{p}^{5}$ have been omitted. Often, for the more highly ionized species, the observed transition energy was not available and we were not able to use our formula for assessing uncertainty. The uncertainties are given in parentheses with respect to the last digit quoted. Thus 2.53(135) implies $2.53 \pm 1.35$ or an uncertainty of more than $50 \%$ as in the O II intercombination transition, $2 \mathrm{p}^{3}{ }^{4} \mathrm{~S}_{3 / 2}^{\mathrm{o}}-2 \mathrm{~s} 2 \mathrm{p}^{4}{ }^{2} \mathrm{~S}_{1 / 2}$. Uncertainties larger than $70 \%$ are expressed in \%. Uncertainties reported as zero imply a value less than one half in the last decimal place reported.

Similarly, in Table 6 (see footnote to abstract) we present adjusted transition rates (in $\mathrm{s}^{-1}$ ) and uncertainties (in parentheses) for O I, Ne III, Mg V, and Si VII. Again, only some transitions are included in the tables. Missing are the transitions from $2 \mathrm{p}^{6}{ }^{1} \mathrm{~S}_{0}$, for example.

\section{Comparison with other theory and experiment}

In Table 6, some of the lines in N I are compared with CIV3, OP, and experiment. The latter measured relative transition probabilities and direct comparison may not be suitable. For $3 \mathrm{~s}-3 \mathrm{p}$ transitions, there is excellent agreement with CIV3 (Hibbert et al. 1991a). It seems that when two experimental values are available for the multiplet, (Musielok et al. 1995, 2000), the present results are in slightly better agreement with the first, even though this is the earlier experiment. For allowed $3 \mathrm{p}-3 \mathrm{~d}$ transitions, we compare only ${ }^{4} \mathrm{P}^{\mathrm{o}}{ }^{4} \mathrm{P}$ where the $g_{J}$ factor indicated some $J$-dependence for the $2 \mathrm{p}^{2}\left({ }^{3} \mathrm{P}\right) 3 \mathrm{~d}{ }^{4} \mathrm{P}$ term. Our
Table 6. Selected multiplet rates for N I compared to experimental and other theoretical data.

\begin{tabular}{|c|c|c|c|c|c|c|}
\hline$g i$ & $g k$ & Present & $x$ & $\mathrm{CIV}^{a}$ & $\mathrm{OP}^{b}$ & $\operatorname{Expt}^{c}$ \\
\hline \multicolumn{7}{|c|}{$2 \mathrm{p}^{2}\left({ }^{3} \mathrm{P}\right) 3 \mathrm{~s}{ }^{4} \mathrm{P}-2 \mathrm{p}^{2}\left({ }^{3} \mathrm{P}\right) 3 \mathrm{p}{ }^{4} \mathrm{D}^{\mathrm{o}}$} \\
\hline 12 & 20 & $2.534(118)$ & 7 & 2.59 & \multirow[t]{9}{*}{1.83} & $2.25(25), 3.17^{d}$ \\
\hline 6 & 8 & $2.531(114)$ & 7 & 2.596 & & $2.21(24)$ \\
\hline 4 & 6 & $1.881(88)$ & 7 & 1.925 & & $1.67(18)$ \\
\hline 2 & 4 & $1.152(55)$ & 7 & 1.179 & & $1.04(11)$ \\
\hline 6 & 6 & $6.546(351)$ & 6 & 6.725 & & $5.95(65)$ \\
\hline 4 & 4 & $1.288(62)$ & 7 & 1.320 & & $1.17(13)$ \\
\hline 2 & 2 & $2.161(97)$ & 7 & 2.211 & & $1.97(22)$ \\
\hline 6 & 4 & $9.662(594)$ & 5 & 9.032 & & $8.83(97)$ \\
\hline 4 & 2 & $3.761(194)$ & 6 & 3.857 & & $3.24(36)$ \\
\hline \multicolumn{7}{|c|}{$2 \mathrm{p}^{2}\left({ }^{3} \mathrm{P}\right) 3 \mathrm{~s}{ }^{4} \mathrm{P}-2 \mathrm{p}^{2}\left({ }^{3} \mathrm{P}\right) 3 \mathrm{p}{ }^{4} \mathrm{~S}^{\mathrm{o}}$} \\
\hline 12 & 4 & $3.722(169)$ & 7 & 3.84 & \multirow[t]{4}{*}{2.37} & $3.68(40), 4.09^{d}$ \\
\hline 6 & 4 & $1.961(94)$ & 7 & 2.017 & & $1.90(21)$ \\
\hline 4 & 4 & $1.196(52)$ & 7 & 1.236 & & $1.29(14)$ \\
\hline 2 & 4 & $5.649(229)$ & 6 & 5.856 & & $5.63(62)$ \\
\hline \multicolumn{7}{|c|}{$2 \mathrm{p}^{2}\left({ }^{3} \mathrm{P}\right) 3 \mathrm{~s}{ }^{2} \mathrm{P}-2 \mathrm{p}^{2}\left({ }^{3} \mathrm{P}\right) 3 \mathrm{p}{ }^{2} \mathrm{D}^{\mathrm{o}}$} \\
\hline 6 & 10 & $2.517(174)$ & 7 & 2.67 & \multirow[t]{4}{*}{2.66} & $2.56(31)$ \\
\hline 4 & 6 & $2.519(170)$ & 7 & 2.679 & & $2.53(28)$ \\
\hline 2 & 4 & $2.139(154)$ & 7 & 2.263 & & $2.14(24)$ \\
\hline 4 & 4 & $3.741(250)$ & 6 & 4.043 & & $3.88(43)$ \\
\hline \multicolumn{7}{|c|}{$2 \mathrm{p}^{2}\left({ }^{3} \mathrm{P}\right) 3 \mathrm{~s}{ }^{2} \mathrm{P}-2 \mathrm{p}^{2}\left({ }^{3} \mathrm{P}\right) 3 \mathrm{p}{ }^{2} \mathrm{P}^{\mathrm{o}}$} \\
\hline 6 & 6 & $3.184(28)$ & 7 & 3.26 & \multirow[t]{5}{*}{3.21} & $2.97(36)$ \\
\hline 4 & 4 & $2.678(32)$ & 7 & 2.752 & & $2.52(28)$ \\
\hline 2 & 2 & $2.146(0)$ & 7 & 2.158 & & $1.98(22)$ \\
\hline 4 & 2 & $1.075(12)$ & 7 & 1.108 & & $.970(107)$ \\
\hline 2 & 4 & $4.871(42)$ & 6 & 5.106 & & $4.64(51)$ \\
\hline \multicolumn{7}{|c|}{$2 \mathrm{p}^{2}\left({ }^{3} \mathrm{P}\right) 3 \mathrm{p}{ }^{4} \mathrm{P}^{\mathrm{o}}-2 \mathrm{p}^{2}\left({ }^{3} \mathrm{P}\right) 3 \mathrm{~d}{ }^{4} \mathrm{P}$} \\
\hline 6 & 6 & $3928(159)$ & 6 & 3.07 & & $2.37(31)$ \\
\hline 4 & 4 & $2.21(100 \%)$ & 3 & 257.0 & & $<60$ \\
\hline 2 & 2 & $5.397(924)$ & 6 & 9.480 & & $3.39(44)$ \\
\hline 6 & 4 & $3.757(363)$ & 6 & 2.740 & & $2.29(30)$ \\
\hline 4 & 2 & $6.751(701)$ & 6 & 4.178 & & $4.01(52)$ \\
\hline 4 & 6 & $7.164(1600)$ & 6 & 10.01 & & $4.18(54)$ \\
\hline 2 & 4 & $9.027(793)$ & 6 & 11.03 & & $5.55(72)$ \\
\hline \multicolumn{7}{|c|}{$2 \mathrm{p}^{2}\left({ }^{3} \mathrm{P}\right) 3 \mathrm{p}{ }^{4} \mathrm{D}^{\mathrm{o}}-2 \mathrm{p}^{2}\left({ }^{3} \mathrm{P}\right) 3 \mathrm{~d}^{2} \mathrm{~F}$} \\
\hline 8 & 8 & $4.846(435)$ & 5 & 4.12 & & $9.20(129)$ \\
\hline 6 & 6 & $1.064(481)$ & 6 & 0.4203 & & $2.26(32)$ \\
\hline 6 & 8 & $6.091(3310)$ & 6 & 5.270 & & $10.8(1.5)$ \\
\hline 4 & 6 & $4.846(100 \%)$ & 5 & 5.548 & & $8.10(1.13)$ \\
\hline
\end{tabular}

${ }^{a}$ A. Hibbert, E. Biemont, M. Godefroid, \& N. Vaeck (1991a). ${ }^{b}$ The Opacity Project Team, The Opacity Project (1995).

${ }^{c}$ J. Musielok, W. L. Wiese, \& G. Veres (1995).

${ }^{d}$ J. Musielok, J. M. Bridges, J. R. Fuhr, \& W. L. Wiese (2000).

present work, unlike the CIV3 calculation (Hibbert et al. 1991a) has correctly identified the very weak line whose transition rate could not be measured. Ignoring this line, the ratio of our present rates and those of experiment vary only between 1.6 to 1.7 whereas the CIV3 rates vary from 1.0-2.8, a much wider range. In the case of the intercombination multiplet, the CIV3 values all have similar magnitude, whereas the present ones are about half the experimental ones, in a range of $0.47-0.60$. Thus the present results are in better relative agreement with experiment.

In Table 7 several multiplets in O II are compared with experiment (Veres et al. 1996) and other theory, namely 
Table 7. Computed multiplet values for O II compared with experimental and other theoretical data.

\begin{tabular}{|c|c|c|c|c|c|c|}
\hline$g i$ & $\overline{g k}$ & Computed & $x$ & Expt. $^{a}$ & $\mathrm{CIV}^{b}$ & $\mathrm{OP}^{c}$ \\
\hline \multicolumn{7}{|c|}{$2 \mathrm{p}^{2}\left({ }^{3} \mathrm{P}\right) 3 \mathrm{~s}{ }^{4} \mathrm{P}-2 \mathrm{p}^{2}\left({ }^{3} \mathrm{P}\right) 3 \mathrm{p}{ }^{4} \mathrm{D}^{\mathrm{o}}$} \\
\hline 12 & 20 & $8.130(32)$ & 7 & 7.29 & 8.48 & 8.32 \\
\hline 6 & 8 & $8.140(32)$ & 7 & 7.18 & 8.49 & 8.33 \\
\hline 4 & 6 & $6.001(19)$ & 7 & 5.43 & 6.26 & 5.86 \\
\hline 2 & 4 & $3.669(11)$ & 7 & 3.40 & 3.82 & 3.49 \\
\hline 6 & 6 & $2.120(13)$ & 7 & 1.87 & 2.22 & 2.46 \\
\hline 4 & 4 & $4.136(19)$ & 7 & 3.76 & 4.32 & 4.41 \\
\hline 2 & 2 & $6.900(25)$ & 7 & 6.21 & 7.20 & 6.94 \\
\hline 6 & 4 & $3.146(24)$ & 6 & 2.99 & 3.31 & 4.04 \\
\hline 4 & 2 & $1.211(6)$ & 7 & 1.22 & 1.27 & 1.37 \\
\hline \multicolumn{7}{|c|}{$2 \mathrm{p}^{2}\left({ }^{3} \mathrm{P}\right) 3 \mathrm{~s}{ }^{4} \mathrm{P}-2 \mathrm{p}^{2}\left({ }^{3} \mathrm{P}\right) 3 \mathrm{p}{ }^{4} \mathrm{P}^{\mathrm{o}}$} \\
\hline 12 & 12 & $9.473(268)$ & 7 & 8.68 & 9.76 & 9.71 \\
\hline 6 & 6 & $6.943(191)$ & 7 & 6.35 & 7.15 & 6.76 \\
\hline 4 & 4 & $1.584(43)$ & 7 & 1.44 & 1.62 & 1.30 \\
\hline 2 & 2 & $1.438(43)$ & 7 & 1.35 & 1.49 & 1.64 \\
\hline 6 & 4 & $4.059(110)$ & 7 & 3.66 & 4.19 & 4.30 \\
\hline 4 & 2 & $8.022(224)$ & 7 & 7.64 & 8.26 & 8.07 \\
\hline 4 & 6 & $2.532(77)$ & 7 & 2.34 & 2.62 & 2.96 \\
\hline 2 & 4 & $3.83(115)$ & 7 & 3.40 & 3.95 & 4.12 \\
\hline \multicolumn{7}{|c|}{$2 \mathrm{p}^{2}\left({ }^{3} \mathrm{P}\right) 3 \mathrm{~s}{ }^{4} \mathrm{P}-2 \mathrm{p}^{2}\left({ }^{3} \mathrm{P}\right) 3 \mathrm{p}{ }^{4} \mathrm{~S}^{\mathrm{o}}$} \\
\hline 12 & 4 & $1.720(207)$ & 8 & 1.65 & 1.82 & 1.77 \\
\hline 6 & 4 & $8.881(112)$ & 7 & 8.56 & 9.37 & 8.74 \\
\hline 4 & 4 & $5.608(65)$ & 7 & 5.34 & 5.95 & 5.93 \\
\hline 2 & 4 & $2.711(30)$ & 7 & 2.61 & 2.88 & 3.00 \\
\hline \multicolumn{7}{|c|}{$2 \mathrm{p}^{2}\left({ }^{3} \mathrm{P}\right) 3 \mathrm{~s}^{2} \mathrm{P}-2 \mathrm{p}^{2}\left({ }^{3} \mathrm{P}\right) 3 \mathrm{p}{ }^{2} \mathrm{D}^{\mathrm{o}}$} \\
\hline 6 & 10 & $9.178(288)$ & 7 & 7.73 & 9.25 & 9.50 \\
\hline 4 & 6 & $9.186(288)$ & 7 & 7.67 & 9.26 & 9.52 \\
\hline 2 & 4 & $7.725(242)$ & 7 & 6.55 & 7.77 & 7.93 \\
\hline 4 & 4 & $1.440(46)$ & 7 & 1.26 & 1.47 & 1.55 \\
\hline \multicolumn{7}{|c|}{$2 \mathrm{p}^{2}\left({ }^{3} \mathrm{P}\right) 3 \mathrm{~s}{ }^{2} \mathrm{P}-2 \mathrm{p}^{2}\left({ }^{3} \mathrm{P}\right) 3 \mathrm{p}{ }^{2} \mathrm{P}^{\mathrm{o}}$} \\
\hline 6 & 6 & $1.275(192)$ & 8 & & 1.29 & 1.33 \\
\hline 4 & 4 & $1.065(16)$ & 8 & 0.956 & 1.08 & 1.10 \\
\hline 2 & 2 & $8.455(127)$ & 7 & & 8.57 & 8.94 \\
\hline 4 & 2 & $4.331(64)$ & 7 & 3.93 & 4.38 & 4.37 \\
\hline 2 & 4 & $2.08(32)$ & 7 & 1.88 & 2.14 & 2.25 \\
\hline \multicolumn{7}{|c|}{$2 \mathrm{p}^{2}\left({ }^{3} \mathrm{P}\right) 3 \mathrm{p}{ }^{2} \mathrm{~S}^{\mathrm{o}}-2 \mathrm{p}^{2}\left({ }^{3} \mathrm{P}\right) 3 \mathrm{~d}{ }^{2} \mathrm{P}$} \\
\hline 3 & 6 & $1.248(11)$ & 8 & 1.14 & 1.50 & 1.24 \\
\hline 2 & 4 & $1.257(13)$ & 8 & 1.12 & 1.50 & 1.24 \\
\hline 2 & 2 & $1.228(6)$ & 8 & 1.17 & 1.48 & 1.25 \\
\hline \multicolumn{7}{|c|}{$2 p^{2}\left({ }^{3} P\right) 3 p{ }^{4} D^{o}-2 p^{2}\left({ }^{3} P\right) 3 d{ }^{4} F$} \\
\hline 20 & 28 & $1.950(27)$ & 8 & 1.96 & 2.01 & 1.99 \\
\hline 8 & 10 & $1.949(27)$ & 8 & 1.94 & 2.01 & 1.99 \\
\hline 6 & 8 & $1.713(24)$ & 8 & 1.82 & 1.77 & 1.71 \\
\hline 4 & 6 & $1.507(21)$ & 8 & 1.41 & 1.55 & 1.50 \\
\hline 2 & 4 & $1.403(19)$ & 8 & 1.40 & 1.45 & 1.40 \\
\hline 8 & 8 & $2.355(31)$ & 7 & 2.44 & 2.46 & 2.80 \\
\hline 6 & 6 & $4.287(58)$ & 7 & 4.18 & 4.45 & 4.82 \\
\hline 4 & 4 & $5.175(71)$ & 7 & 5.07 & 5.35 & 5.57 \\
\hline 8 & 6 & $1.387(18)$ & 6 & 1.56 & 1.46 & 1.88 \\
\hline 6 & 4 & $3.229(43)$ & 6 & 4.32 & 3.37 & 3.93 \\
\hline
\end{tabular}

Table 7. continued.

\begin{tabular}{|c|c|c|c|c|c|c|}
\hline$g i$ & $g k$ & Computed & $x$ & Expt. $^{a}$ & $\mathrm{CIV}^{b}$ & $\mathrm{OP}^{c}$ \\
\hline \multicolumn{7}{|c|}{$2 p^{2}\left({ }^{3} \mathrm{P}\right) 3 \mathrm{p}{ }^{4} \mathrm{D}^{\mathrm{o}}-2 \mathrm{p}^{2}\left({ }^{3} \mathrm{P}\right) 3 \mathrm{~d}{ }^{4} \mathrm{D}$} \\
\hline 20 & 20 & $4.360(152)$ & 7 & 4.35 & 4.88 & 5.77 \\
\hline 8 & 8 & $5.021(169)$ & 7 & 5.06 & 5.14 & 4.89 \\
\hline 6 & 6 & $1.760(68)$ & 7 & 1.98 & 2.13 & 3.31 \\
\hline 4 & 4 & $1.347(50)$ & 7 & 1.46 & 1.58 & 2.34 \\
\hline 2 & 2 & $1.450(55)$ & 7 & 1.79 & 1.95 & 2.93 \\
\hline 8 & 6 & $9.063(304)$ & 6 & 10.4 & 11.0 & 10.0 \\
\hline 6 & 4 & $1.894(63)$ & 7 & 1.65 & 2.18 & 2.02 \\
\hline 4 & 2 & $2.287(81)$ & 7 & 2.10 & 2.80 & 2.91 \\
\hline 6 & 8 & $5.665(211)$ & 6 & 5.97 & 6.01 & 8.24 \\
\hline 4 & 6 & $4.789(177)$ & 6 & 5.50 & 6.26 & 13.6 \\
\hline 2 & 4 & $7.986(262)$ & 6 & 6.85 & 9.42 & 14.7 \\
\hline \multicolumn{7}{|c|}{$2 \mathrm{p}^{2}\left({ }^{3} \mathrm{P}\right) 3 \mathrm{p}{ }^{4} \mathrm{P}^{\mathrm{o}}-2 \mathrm{p}^{2}\left({ }^{3} \mathrm{P}\right) 3 \mathrm{~d}{ }^{4} \mathrm{P}$} \\
\hline 12 & 12 & $10.890(336)$ & 7 & & 9.63 & 9.92 \\
\hline 6 & 6 & $2.506(82)$ & 7 & 2.49 & 3.00 & 6.86 \\
\hline 4 & 4 & $1.929(112)$ & 7 & 3.76 & 1.36 & 1.33 \\
\hline 2 & 2 & $8.492(274)$ & 7 & & 5.60 & 1.69 \\
\hline 6 & 4 & $1.904(57)$ & 7 & 1.94 & 2.39 & 4.45 \\
\hline 4 & 2 & $2.218(83)$ & 7 & 1.65 & 3.98 & 8.40 \\
\hline 4 & 6 & $7.575(204)$ & 7 & 7.27 & 6.64 & 2.97 \\
\hline 2 & 4 & $8.360(232)$ & 7 & 8.39 & 7.37 & 4.19 \\
\hline \multicolumn{7}{|c|}{$2 \mathrm{p}^{2}\left({ }^{3} \mathrm{P}\right) 3 \mathrm{p}{ }^{4} \mathrm{P}^{\mathrm{o}}-2 \mathrm{p}^{2}\left({ }^{3} \mathrm{P}\right) 3 \mathrm{~d}{ }^{4} \mathrm{D}$} \\
\hline 12 & 20 & $1.249(6)$ & 8 & & 1.33 & 1.53 \\
\hline 6 & 8 & $1.375(4)$ & 8 & 1.22 & 1.40 & 1.52 \\
\hline 4 & 6 & $3.473(43)$ & 7 & 2.89 & 4.74 & 10.7 \\
\hline 2 & 4 & $1.480(15)$ & 7 & 3.33 & 2.74 & 6.42 \\
\hline 6 & 6 & $6.120(20)$ & 7 & 1.98 & 6.25 & 4.55 \\
\hline 4 & 4 & $9.093(32)$ & 7 & 8.40 & 9.35 & 8.17 \\
\hline 2 & 2 & $5.556(48)$ & 7 & 4.68 & 8.63 & 1.28 \\
\hline 6 & 4 & $3.201(22)$ & 7 & & 2.60 & 7.58 \\
\hline 4 & 2 & $7.988(64)$ & 7 & 7.08 & 6.03 & 2.54 \\
\hline \multicolumn{7}{|c|}{$2 p^{2}\left({ }^{3} \mathrm{P}\right) 3 \mathrm{p}{ }^{4} \mathrm{P}^{\mathrm{o}}-2 \mathrm{p}^{2}\left({ }^{3} \mathrm{P}\right) 4 \mathrm{~s}{ }^{4} \mathrm{P}$} \\
\hline 6 & 6 & $5.32(101)$ & 7 & 4.92 & & 4.77 \\
\hline 4 & 4 & $1.220(231)$ & 7 & 1.00 & & 0.90 \\
\hline 2 & 2 & $1.063(235)$ & 7 & 1.06 & & 1.12 \\
\hline 6 & 4 & $2.794(539)$ & 7 & 2.89 & & 3.02 \\
\hline 4 & 2 & $5.67(109)$ & 7 & 5.55 & & 5.58 \\
\hline 4 & 6 & $2.087(397)$ & 7 & 2.02 & & 2.06 \\
\hline 2 & 4 & $3.049(582)$ & 7 & & & \\
\hline \multicolumn{7}{|c|}{$2 p^{2}\left({ }^{3} \mathrm{P}\right) 3 \mathrm{p}{ }^{2} \mathrm{D}^{\mathrm{o}-}-2 \mathrm{p}^{2}\left({ }^{3} \mathrm{P}\right) 3 \mathrm{~d}{ }^{2} \mathrm{~F}$} \\
\hline 10 & 14 & $1.338(4)$ & 8 & & 1.14 & 1.40 \\
\hline 6 & 8 & $1.283(5)$ & 8 & 1.01 & 1.24 & 1.40 \\
\hline 4 & 6 & $8.699(13)$ & 7 & & 9.36 & 13.2 \\
\hline 6 & 6 & $5.418(9)$ & 6 & 4.33 & 5.80 & 9.14 \\
\hline \multicolumn{7}{|c|}{$2 \mathrm{p}^{2}\left({ }^{3} \mathrm{P}\right) 3 \mathrm{p} \quad{ }^{2} \mathrm{D}^{\mathrm{o}}-2 \mathrm{p}^{2}\left({ }^{3} \mathrm{P}\right) 4 \mathrm{~s}^{2} \mathrm{P}$} \\
\hline 6 & 4 & $1.161(156)$ & 8 & 8.63 & & 11.6 \\
\hline 4 & 2 & $1.298(175)$ & 8 & 1.09 & & 1.29 \\
\hline 4 & 4 & $1.245(165)$ & 7 & & & \\
\hline \multicolumn{7}{|c|}{$2 \mathrm{p}^{2}\left({ }^{3} \mathrm{P}\right) 3 \mathrm{p}{ }^{4} \mathrm{~S}^{\mathrm{o}}-2 \mathrm{p}^{2}\left({ }^{3} \mathrm{P}\right) 3 \mathrm{~d}{ }^{4} \mathrm{P}$} \\
\hline 4 & 12 & $4.976(26)$ & 7 & & 5.48 & 6.26 \\
\hline 4 & 6 & $5.160(27)$ & 7 & & 5.43 & 6.22 \\
\hline 4 & 4 & $4.824(22)$ & 7 & 4.17 & 5.40 & 6.29 \\
\hline 4 & 2 & $4.728(29)$ & 7 & 4.41 & 5.79 & 6.35 \\
\hline
\end{tabular}


Table 7. continued.

\begin{tabular}{ccccccc}
\hline \hline$g i$ & $g k$ & Computed & $x$ & Expt. $^{a}$ & CIV3 $^{b}$ & OP $^{c}$ \\
\hline $2 \mathrm{p}^{2}\left({ }^{3} \mathrm{P}\right) 3 \mathrm{p}$ & ${ }^{4} \mathrm{~S}^{\mathrm{o}}-2 \mathrm{p}^{2}\left({ }^{3} \mathrm{P}\right) 4 \mathrm{~s}^{4} \mathrm{P}$ \\
4 & 12 & $3.526(512)$ & 7 & 2.89 & & 4.10 \\
4 & 6 & $3.658(532)$ & 7 & 2.97 & & 4.15 \\
4 & 4 & $3.437(499)$ & 7 & 3.10 & & 4.07 \\
4 & 2 & $3.306(480)$ & 7 & 2.25 & & 4.02 \\
\multicolumn{7}{c}{} \\
$2 \mathrm{p}^{2}\left({ }^{3} \mathrm{P}\right) 3 \mathrm{p}^{2} \mathrm{P}^{\mathrm{o}}-2 \mathrm{p}^{2}\left({ }^{3} \mathrm{P}\right) 3 \mathrm{~d}{ }^{2} \mathrm{P}$ \\
6 & 6 & $5.806(440)$ & 7 & 4.43 & 4.64 & 6.53 \\
4 & 4 & $4.260(333)$ & 7 & 3.29 & 3.38 & 5.40 \\
2 & 2 & $4.032(165)$ & 7 & 3.02 & 3.22 & 4.44 \\
4 & 2 & $1.957(80)$ & 7 & 1.37 & 1.56 & 2.20 \\
2 & 4 & $1.455(204)$ & 7 & 1.16 & 1.20 & 1.09 \\
$2 \mathrm{p}^{2}\left({ }^{3} \mathrm{P}\right) 3 \mathrm{p}$ & ${ }^{2} \mathrm{P}^{\mathrm{o}}-2 \mathrm{p}^{2}\left({ }^{3} \mathrm{P}\right) 3 \mathrm{~d}{ }^{2} \mathrm{D}$ & & \\
6 & 10 & $9.245(172)$ & 7 & 7.12 & 8.62 & 9.78 \\
4 & 6 & $9.225(28)$ & 7 & 7.15 & 8.61 & 9.78 \\
2 & 4 & $7.114(195)$ & 7 & 5.40 & 6.67 & 8.16 \\
4 & 4 & $2.162(192)$ & 7 & 1.67 & 1.96 & 1.62 \\
\hline
\end{tabular}

${ }^{a}$ Veres \& Wiese (1996).

${ }^{b}$ Bell et al. (1994).

${ }^{c}$ Opacity Project Team (unpublished).

CIV3 (Bell 1994) and OP (Opacity Project 1995). For the $3 \mathrm{~s}-3 \mathrm{p}$ transitions there generally is good agreement amongst the theories, with the present results slightly closer to experiment than the others. For $3 \mathrm{p}-3 \mathrm{~d}$ transitions, some of our results (like ${ }^{2} \mathrm{~S}^{\mathrm{o}}{ }^{2} \mathrm{P}$ ) are in close agreement with the OP values, differing from both CIV3 and experiment, whereas for ${ }^{4} \mathrm{P}^{\mathrm{o}}{ }^{4} \mathrm{P}$ CIV3 3 and OP occasionally differ by a factor of almost two, whereas some of the present lines are in good agreement with experiment. Similar remarks apply to the ${ }^{4} \mathrm{P}^{\mathrm{o}}{ }^{4} \mathrm{D}$ multiplet. O II, as a spectrum is not highly relativistic, the largest difference between $L S$ and $L S J g_{J}$ factors occurring for the $2 \mathrm{p}^{2}\left({ }^{3} \mathrm{P}\right) 3 \mathrm{~d}{ }^{4} \mathrm{P}$ and ${ }^{4} \mathrm{D}$. Except for the mixing of these two terms, it is then largely a matter of how well the theories have captured the effect of correlation. No parentchanging transitions were considered.

In Table 8 we compare oscillator strengths ( $f$-values) for three transitions. The calculations reported by Jönsson \& Godefroid (2000) are the most accurate non-relativistic calculations published todate, an approximation valid for the transitions considered. There is excellent agreement with our present results. The experimental values are not satisfactory, though the most recent time-resolved laser spectroscopy experiment has a large error bar, bringing its upper limit close to our theoretical value.

\section{Conclusions}

Breit-Pauli energy levels and E1 transition rates have been critically evaluated. Energy levels frequently differ from the observed by only $300-400 \mathrm{~cm}^{-1}$, a considerable improvement over other calculations that include relativistic
Table 8. Comparison of oscillator strengths for three transitions in O I. Note the different units for each transition.

\begin{tabular}{|c|c|c|c|}
\hline$f_{1}$ & $f_{\mathrm{v}}$ & Method & Ref. \\
\hline \multicolumn{4}{|c|}{$2 \mathrm{p}^{4}{ }^{3} \mathrm{P}-2 \mathrm{p}^{3}\left({ }^{4} \mathrm{~S}\right) 3 \mathrm{~s}{ }^{3} \mathrm{~S}^{\circ}\left(f \times 10^{2}\right)$} \\
\hline \multicolumn{4}{|c|}{4.7935 .136 Present } \\
\hline 4.19 & & $\mathrm{MCHF}+\mathrm{BP}$ & Froese Fischer (1987) \\
\hline 4.96 & 5.48 & R-matrix & Bell \& Hibbert (1990) \\
\hline 5.29 & 5.70 & CIV3 & Hibbert et al. (1991b) \\
\hline 5.12 & & $\mathrm{OP}$ & Butler \& Zeippen (1991) \\
\hline 5.22 & & Superstructure & Biémont \& Zeippen (1992) \\
\hline 5.47 & & R-matrix & Nahar (1998) \\
\hline 4.20 & 5.06 & $\mathrm{MCHF}+\mathrm{CI}$ & Jönsson \& Godefroid (2000) \\
\hline $4.5(1$ & & Exp (Line adsorption) & Clyne et al. (1976) \\
\hline 5.30( & & Exp (Adsorption) & Jenkins (1985) \\
\hline 5.19 & & CNO compilation & Wiese et al. (1996) \\
\hline \multicolumn{4}{|c|}{$2 \mathrm{p}^{3}\left({ }^{4} \mathrm{~S}\right) 3 \mathrm{~s}{ }^{5} \mathrm{~S}^{\mathrm{O}}-2 \mathrm{p}^{3}\left({ }^{4} \mathrm{~S}\right) 3 \mathrm{p}{ }^{5} \mathrm{P}(f \times 10)$} \\
\hline \multicolumn{4}{|c|}{9.6729 .065 Present } \\
\hline 9.76 & 7.68 & R-matrix & Bell \& Hibber \\
\hline 10.1 & 9.23 & CIV3 & Hibbert et al. (19 \\
\hline 9.78 & & OP & Butler \& Zeippen (1991) \\
\hline 9.90 & & Superstructure & Biémont \& Zeippen (1992) \\
\hline 9.50 & 9.46 & $\mathrm{MCHF}$ & Froese Fischer (1999) \\
\hline 9.62 & 9.55 & $\mathrm{MCHF}+\mathrm{CI}$ & on \& Godefroid (2000) \\
\hline 10.0 & & CNO compilation & t al. (1996) \\
\hline 7.00 & & HFD & der et al. (1971) \\
\hline \multicolumn{4}{|c|}{$2 p^{3}\left({ }^{4} S\right) 3 s{ }^{3} S^{o}-2 p^{3}\left({ }^{4} S\right) 3 p{ }^{3} P$} \\
\hline \multicolumn{4}{|c|}{1.0241 .052 Present } \\
\hline 1.03 & 0.827 & R-matrix & Bell \& Hibbert (1990) \\
\hline 1.08 & 1.07 & CIV3 & Hibbert et al. (1991b) \\
\hline 1.05 & & OP & Butler \& Zeippen (1991) \\
\hline 0.929 & & Superstructure & Biémont \& Zeippen (1992) \\
\hline 1.03 & 1.04 & $\mathrm{MCHF}$ & Froese Fischer (1999) \\
\hline 1.03 & 1.08 & $\mathrm{MCHF}+\mathrm{CI}$ & Jönsson \& Godefroid (2000) \\
\hline 1.03 & & CNO Compilation & Wiese et al. (1996) \\
\hline 0.80 & & HFD & Bromander et al. (1971) \\
\hline 0.820 & $(30)$ & LIF & Bischel et al. (1981) \\
\hline 0.890 & (100) & TRLS & Kröll et al. (1985) \\
\hline
\end{tabular}

Note:

HFD High Frequency Deflection Technique

LIF Laser Induced Fluorescence

TRLS Time REsolved Laser Spectroscopy

effects. Data for the N-like $(Z=7-17)$ and O-like $(Z=8-$ $20)$ sequences are available at our website and provide information for many transitions missing in the NIST tabulations.

\section{References}

Biémont, E., \& Zeippen, C. J. 1992, A\&A, 264, 850

Bischel, W. K., Perry, B. E., \& Crossley, D. R. 1981, Chem. Phys. Lett., 82, 85

Bell, K. L., \& Hibbert, A. 1990, J. Phys. B 23, 2673

Bell, K. L., Hibbert, A., Stafford R. P., \& Mclaughlin B. M. 1994, Phys. Scr., 50, 343

Bromander, J., Duric, N., Erman, P., \& Larsson, M. 1971, Phys. Scr., 17, 119 
Butler, K., \& Zeippen, C. J. 1991, J. Phys. IV France, 1, C1141

Clyne, M. A. A., \& Piper, L. G. 1976, J. Chem. Soc. Faraday Tran. II, 72, 2178

Drake, G. W. R. 1972, Phys. Rev. A, 5, 1979

Froese Fischer, C. 1987, J. Phys. B, 20, 1193

Froese Fischer, C. 1999, Phys. Scr., T83, 49

Froese Fischer, C., Brage, T., \& Jönsson, P. 1997, Computational Atomic Structure - An MCHF Approach (Institute of Physics Publishing, Bristol)

Hibbert, A., Biémont, E., Godefroid, M., \& Vaeck, N. 1991, A\&AS, 88, 505

Hibbert, A., Biémont, E., Godefroid, M., \& Vaeck, N. 1991, J. Phys. B, 24, 3943

Jenkins, D. B. 1985, J. Quant. Spectrosc. Radiat. Transfer, 34,55

Jönsson, P., \& Godefroid, M. R. 2000, Molecular Phys., 98, 1141
Kröll, S., Lundberg, H., Persson, A., \& Svanberg, S. 1985, Phys. Rev. Lett., 55, 284

Muslielok, J., Wiese, W. L., \& Veres, G. 1995, Phys. Rev. A, 51,3588

Musielok, J., Bridges, J. M., Fuhr, J. R., \& Wiese, W. L. 2000, Phys. Rev. A, 61, 044502

Nahar, S. N. 1998, Phys. Rev. A, 58, 3766

Opacity Project Team, 1995, The Opacity Project (Inst. of Physics, Bristol), vol. 1

Seaton, M. J. 1987, J. Phys. B, 20, 6363

Tachiev, G., \& Froese Fischer, C. 1999, J. Phys. B, 32, 5805

Tachiev, G., \& Froese Fischer, C. 2000, J. Phys. B, 33, 2419

Tachiev, G., \& Froese Fischer, C. 2001, Can. J. Phys., 79, 955

Veres, G., \& Wiese, W. L. 1996, Phys. Rev., 54, 1999

Wiese, W. L., Fuhr, J. R., \& Deters, T. M. 1996, J. Phys. Chem. Ref. Data, Monograph, 7 